\title{
A LEITURA DO TEXTO NÃO-VERBAL IMAGÉTICO EM LIVROS DIDÁTICOS: REFLEXÕES A PARTIR DE UM OLHAR DISCURSIVO
}

\author{
CÁRMEN LÚCIA HERNANDES AGUSTINI ${ }^{1}$ \\ ÉRICA DANIELA DE ARAUJO², JOÃO DE DEUS LEITE ${ }^{3}$
}

\author{
Programa de Pós-Graduação em Estudos Linguísticos \\ Universidade Federal de Uberlândia, Av. João Naves de Ávila, 2121 - 38408-144 \\ Campus Santa Mônica, Uberlândia-MG - Brasil \\ carmen.agustinieufu.br, ericadaniela_araujodyahoo.com.br , \\ jdmilk@gmail.com
}

\begin{abstract}
Resumo. Neste artigo, propomo-nos, a partir da perspectiva teórica da Análise de Discurso concebida por Pêcheux, realizar um exercício de análise sobre o modo como as práticas pedagógicas apresentadas em um livro didático da educação básica brasileira, na edição direcionada ao professor, abordam o trabalho sobre a leitura-interpretação do texto não-verbal imagético. Nesse exercício, problematizamos a tomada do texto não-verbal imagético como uma mera ilustração do texto verbal, o que aponta para um reducionismo da concepção de imagem à transparência do mostrável. De nossa perspectiva teórica, a imagem não é transparente, porque é cifra da história e, por isso, preconizamos uma hiância estrutural entre língua e imagem. Nesse sentido, além de questionarmos em que medida o trabalho de leitura-interpretação do texto não-verbal imagético ganha operacionalização em um livro didático de Língua Portuguesa da educação básica, visamos a oferecer parâmetros para uma prática de ensino que se desloque do aspecto factual da leitura-interpretação para o seu aspecto relacional e discursivo, a fim de explicitar em que medida o professor pode e deve considerar diferentes efeitos de sentido que o texto não-verbal imagético pode suscitar e, assim procedendo, contribuir para a formação do aluno como leitor.
\end{abstract}

Palavras-chave: livro didático; texto; não-verbal; leitura; interpretação; ensino.
Abstract. In this article, we propose, from the theoretical perspective of Discourse Analysis designed by Pêcheux, conduct an analytical exercise on how pedagogical practices presented in a textbook of Brazilian Basic

\footnotetext{
${ }^{1}$ Doutora em Linguística pela Unicamp; professora no Programa de Pós-Graduação em Estudos Linguísticos da Universidade Federal de Uberlândia. http://lattes.cnpq.br/2810007575519305.

${ }^{2}$ Doutoranda em Estudos Linguísticos na UFU; professora no Centro Federal de Educação Tecnológica de Minas Gerais - CEFET-MG, campus Araxá-MG. http://lattes.cnpq.br/9393507013247168.

${ }^{3}$ Doutor em Estudos Linguísticos pela UFU; professor na UFT. http://lattes.cnpq.br/8799618505666633.
} 
Education - issue directed to the teacher - approach the work of readinginterpretation of imagetic non-verbal text. In this exercise, we question how the imagetic non-verbal text is considered as a mere illustration of the verbal text, which points to a reductionism of the conception of image towards the transparency of the showable. From our theoretical perspective, image is not transparent because it is a cipher of history and therefore we advocate a structural hiatus between language and image. In this sense, and to question to what extent the work of reading-interpretation of imagetic nonverbal text becomes operationalized in Portuguese Basic Education textbook, we aim to provide parameters for a teaching practice that moves from a factual aspect of reading- interpretation to its relational and discursive aspect. Our objective is to elicit to what extent the teacher can and should consider different effects of meaning that non-verbal imagetic text may raise and, in so doing, contribute to the formation of the student as a reader.

Keywords: textbook; verbal text; imagetic text; reading; interpretation; teaching.

\section{Considerações iniciais}

No presente artigo, analisamos ${ }^{4}$, tendo em vista a perspectiva teórica da Análise de Discurso, doravante AD, de que modo as práticas pedagógicas de ensino, apresentadas em um livro didático da educação básica, na edição direcionada ao professor, abordam o trabalho sobre a leitura-interpretação de textos não-verbais, particularmente em relação aos textos imagéticos. Em outros termos, questionamos: como o livro didático apresenta e explora esse tipo de texto? O texto não-verbal imagético, no livro aqui analisado, como demonstraremos mais adiante, é tratado como mera ilustração do texto verbal, como tentativa de um resgate conteudístico, e não como uma forma de linguagem que significa em sua especificidade própria, encerrando funcionamentos específicos.

Nos livros didáticos consultados, verificamos que textos não-verbais imagéticos são tratados comumente como repasse de textos verbais, funcionando como mera ilustração, conforme apontado por Rodrigues (2008). Ante essa verificação, recortamos uma passagem do livro "Português: Linguagens", de William Roberto Cereja e Thereza Cochar Magalhães, publicado em 2006, para analisarmos e, assim procedendo, mostrar que esse repasse é um efeito da relação automatizada estabelecida historicamente entre essas formas de linguagem. Nossa análise mostra a hiância constitutiva na relação entre o texto não-verbal imagético e o texto verbal, de modo a evidenciar que não há uma traduzibilidade termo a termo possível de um para outro. A discursivização do texto nãoverbal imagético é uma operação que produz um resto inalienável.

\footnotetext{
${ }^{4}$ É válido salientar que a análise se sustenta em um recorte. No entanto, esse recorte mostra-se representativo do modo predominante de trabalho sobre a leitura-interpretação de textos não-verbais em livros didáticos, dado que houve recorrência nos livros didáticos por nós observados e analisados. Citamos dois, além daquele eleito para análise: BELTRÃO, E.S.; GORDILHO, T. Diálogo: língua portuguesa $-9^{\circ}$ ano. São Paulo: FTD, 2009 e SOARES, M. Português: uma proposta para o letramento - $9^{\circ}$ ano. São Paulo: Moderna, 2002.
} 
Nesse sentido, há uma problemática epistemológica da e sobre a imagem a ser considerada, já que muitas análises sobre essa temática, no campo de estudos discursivos ou em outros, embora abordem a importância de sua significância própria, buscam, muitas vezes, referendar uma teoria em vez de enfrentar os problemas que tais questões colocam ao trabalho com a imagem, de modo a imprimir discussões epistemológicas sobre suas especificidades. Coadunamos com a perspectiva de que a linguagem verbal é o interpretante de todos os outros sistemas semiológicos, mas asseveramos a impossibilidade de recobrimento de um por outro, já que significam de modos distintos. Logo, ao considerarmos que o estudo sobre o texto não-verbal imagético (com)porta um problema epistemológico, podemos nos questionar como isso pode afetar o campo educacional?

Como já dito anteriormente, essas formas textuais possuem funcionamentos específicos, bem como modos de significância particulares: ler um texto não-verbal imagético é diferente de ler um texto verbal, uma vez que os recursos de leiturainterpretação daquele não são recobertos pelos recursos deste. Dito de outro modo, há uma hiância estrutural entre o texto não-verbal imagético e o texto verbal, o que produz efeitos para o próprio ato de ler-interpretar. Diante disso, analisamos em que medida a leitura-interpretação de textos não-verbais imagéticos ganha operacionalização em um livro didático de Língua Portuguesa, no que concerne aos aspectos pedagógicos sobre os quais se embasam.

\section{A questão discursiva e o texto não-verbal imagético}

Tendo em vista o exposto, com o presente tópico, traçamos caminhos possíveis oferecidos pela $\mathrm{AD}$ para problematizarmos o texto não-verbal imagético como prática discursiva ${ }^{5}$. Mais: em que medida o aporte teórico-metodológico da AD pode propiciar uma abordagem de leitura-interpretação do texto não-verbal imagético na qual as especificidades desse tipo de texto sejam preservadas e consideradas.

Como dito anteriormente, há uma problemática epistemológica do e sobre o texto não-verbal imagético, qual seja: a de que muitos estudos, sejam eles do campo discursivo ou não, embora ressaltem a especificidade do não-verbal como materialidade significante, acabam por produzir categorizações bastante rígidas e por propor trajetos de leiturainterpretação um tanto "estabilizados", de modo a não enfrentar o texto não-verbal imagético e a não expor a diferença. Contudo, o texto não-verbal imagético furta-se a essas categorizações, produzindo efeitos de sentidos que escapam a um a priori. Assim, a $\mathrm{AD}$, por estar interessada em analisar os efeitos de sentido possíveis e por apostar no funcionamento do objeto simbólico, coloca-se em condição privilegiada para trabalhar essa problemática, embora também devamos questionar em que medida essa problemática se faz possível.

\footnotetext{
${ }^{5}$ Conforme Orlandi (1995, p. 46), “a noção de prática permite que se estenda a reflexão sobre os processos de produção de sentidos sem o efeito da dominância do verbal, já que por ela não trabalhamos mais com textos, mas com práticas discursivas (sejam verbais ou não)".
} 
Nesse sentido, uma questão que se coloca, de saída, é: como a imagem significa? As condições de sua produção, assim como os dizeres sobre a imagem, historicizam-na. A imagem, embora possua especificidades próprias à sua forma de ser linguagem, constituirá um texto não-verbal se a história a alçar a essa condição. Por isso, a imagem não significa por imanência, mas em relação à história e às condições de sua produção e/ou leitura-interpretação; daí ela não ser meramente retratação/mostração, mas coconstrução que refrata o real.

Em sua teorização, Pêcheux (1999) discorre brevemente sobre a imagem. Segundo ele,

a questão da imagem encontra assim a análise de discurso por outro viés: não mais a imagem legível na transparência, por que um discurso a atravessa e a constitui, mas a imagem opaca e muda, quer dizer, aquela da qual a memória "perdeu" o trajeto de leitura. (PÊCHEUX, 1999, p. 55, grifos nossos)

Nessa citação, Pêcheux abre vias para pensarmos que a problemática da imagem, como texto não-verbal, é algo que precisa ser enfrentado e que ela encontra "a análise de discurso por outro viés". Esse encontro acontece por outro viés, porque a teoria semântica elaborada por esse autor apresenta a língua como base dos processos discursivos. Por exemplo, no livro "O discurso: estrutura ou acontecimento?" (2008 [1983]), Pêcheux, ao analisar o enunciado "on a gangê" [Ganhamos!] e como este migra do esporte para a arena política, trabalha a noção de discurso como um ponto de encontro entre uma memória e uma atualidade, como estrutura e acontecimento. Pêcheux toma como ponto de referência a linguagem verbal para pensar a produção de discurso e como o discurso funciona. Nesse sentido, trazer os estudos de Pêcheux para pensarmos o texto não-verbal imagético não é algo que se faça por transposição; é preciso concebê-lo em suas especificidades. Assim, é necessário questionar como a imagem constitui-se como um ponto de encontro entre uma memória e uma atualidade? Ou seja, como ela constitui-se discurso?

Logo, tratar o discurso como estrutura e acontecimento é investir na possibilidade de que há memória sendo atualizada. Nessa medida, indagamos: isso acontece no texto não-verbal imagético? O que é atualizado/reatualizado em um texto não-verbal imagético? Esses questionamentos tornam-se relevantes, uma vez que o discurso é constituído de uma base material porosa, o que possibilita que outros sentidos ali possam emergir. E no texto não-verbal imagético, como isso ocorre? Ao que parece, o texto nãoverbal imagético não portaria uma recursividade, no sentido de um "dizer" que se estabiliza, o que coloca a imagem, como texto, na condição de uma prática opaca e muda, “aquela da qual a memória 'perdeu' o trajeto de leitura”, ou seja, é devido a algo dessa opacidade própria da linguagem que faz com que a imagem "perca" o trajeto de leiturainterpretação. Assim, "o choque opaco do acontecimento televisual é também algo que não se inscreve, na medida em que está sempre 'já lá”" (PÊCHEUX, 1999, p. 55).

Em realidade, ao apostar no caráter opaco da linguagem, Pêcheux opõe-se aos pressupostos da Análise de Conteúdo que apregoam, entre outros aspectos, a imanência e a unicidade do sentido, bem como a transparência da linguagem. Logo, vejamos o que 
Orlandi (1999) pontua acerca das diferenças entre a Análise de Discurso e a Análise de Conteúdo. De acordo com ela,

A análise de conteúdo, como sabemos, procura extrair sentidos dos textos, respondendo à questão: o que este texto quer dizer? Diferentemente da análise de conteúdo, a Análise de Discurso considera que a linguagem não é transparente. Desse modo, ela não procura atravessar o texto para encontrar um sentido do outro lado. A questão que se coloca é: como este texto significa? Há aí um deslocamento, já prenunciado pelos formalistas russos, onde a questão a ser respondida não é "o quê", mas "como". Para responder, ela não trabalha com os textos apenas como ilustração ou como documento de algo que já está sabido em outro lugar e que o texto exemplifica. Ela produz um conhecimento a partir do próprio texto, porque o vê como tendo uma materialidade simbólica própria e significativa, como tendo uma espessura semântica: ela o concebe em sua discursividade (ORLANDI, 1999, p. 17-18, grifos nossos).

Há muitas análises que ficam no nível da Análise de Conteúdo, presumindo que o sentido é único e imanente. Nesse sentido, o texto não-verbal imagético é tido como mera ilustração do texto verbal, um decalque exato, já que o interesse é compreender um conteúdo e referendar o que fora discursivizado a partir do texto não-verbal imagético. Já a Análise de Discurso, por sua vez, aborda o funcionamento do objeto simbólico. Sendo assim, não é possível estabelecer a priori esse funcionamento. Logo, o texto não-verbal imagético é tratado em sua "materialidade simbólica própria e significativa", considerando a sua opacidade específica e a sua "espessura semântica".

Na terceira época de sua elaboração teórica, Pêcheux, filiado ao pensamento de Milner (1987), toma partido pelo real de modo que o real toma lugar de prevalência sobre o imaginário e o simbólico. Para ele, "todo enunciado é intrinsecamente suscetível de tornar-se outro, diferente de si mesmo, se deslocar discursivamente de seu sentido para derivar para um outro" (PÊCHEUX, 2008 [1983], p. 53). Nesse sentido, pensando o texto não-verbal imagético como prática discursiva, podemos dizer que o texto imagético também é constituído por um real, algo "indizível-invisível” (Cf. AGUSTINI, 2007), que dimensiona sua opacidade constitutiva. Com efeito, a incompletude da imagem sustentase no não-mostrado, naquilo que não se apresenta, mas que não cessa de ali significar. Assim, há a possibilidade mesma de o sentido ser sempre outro, devido à deriva na leiturainterpretação da imagem. Nessa perspectiva, o texto imagético é desde-sempre-já um corte no real, simbolizando-o e, assim, projetando-lhe certo imaginário.

Assim sendo, é necessário que haja uma relação de sustentação entre dizívelvisível para que a imagem possa cumprir sua função de "comprovação" no espaço de uma instituição. O testemunho da imagem reside no fato de somente poder mostrar em nome de um não poder tudo mostrar; ela é corte no real e, por isso, sempre-já simbólica e imaginária. As instituições que colocam em cena a imagem (re)cortam-na para fazê-la significar em certa direção; no entanto, não há garantia de que os sentidos pretendidos pela instituição sejam (re)produzidos no mo(vi)mento de leitura-interpretação do texto não-verbal imagético; há real da imagem em jogo. Portanto, nessa perspectiva, há discursos que circulam socialmente também via imagem. A imagem, além de ser 
permeada por discursos, é também, ao mesmo tempo, discurso. Ela "mexe" (n)as possibilidades de leitura-interpretação; é heterogênea e, por isso, é im-possível o fechamento de sua leitura-interpretação: sentidos se colocam em mo(vi)mento na e pela im-possibilidade ${ }^{6}$ de seu fechamento. Esse funcionamento equívoco da imagem a faz matéria significante, a faz discurso, na história.

Nessa medida, os apontamentos de Jean Davallon, no livro "O Papel da Memória", publicado em português em 1999, são significativos para salientar o que discutimos neste artigo. Segundo ele, a imagem é operadora de memória social; para além do que a imagem pode representar ou informar, é preciso considerar "sua eficácia simbólica" (DAVALLON, 1999, p. 28), isso porque não há encaixe perfeito entre verbal e não-verbal imagético; há redes de memória funcionando, que afetam aqueles que lêem e que, por isso, não fecha a leitura-interpretação em uma possibilidade.

Aquele que observa uma imagem desenvolve uma atividade de produção de significação; esta não lhe é transmitida ou entregue toda pronta. Esse estado de coisas abre, como aliás insistem em nos fazer observar, a uma liberdade de interpretação (o que quer dizer que o conteúdo "legível", ou antes "dizível", pode variar conforme as leituras), mas o que faz também - e não se poderia esquecer este ponto - com que a imagem comporte um programa de leitura. (DAVALLON, 1999 , p. 28-29)

Dessa forma, a AD desfaz a ilusão da transparência do texto não-verbal imagético e propõe o não fechamento da sua leitura-interpretação; a imagem, na condição de texto não-verbal, fecha-se como texto, mas não discursivamente. "Face ao dispositivo teórico da interpretação, há uma parte que é de responsabilidade do analista e uma parte que deriva da sua sustentação no rigor do método e no alcance teórico da Análise de Discurso" (ORLANDI, 1999, p. 27). Ou seja, as análises configuram-se, como leiturasinterpretações possíveis, por isso não se fecham como "verdades", já que o discurso não é essência; é relação de produção de sentidos e efeitos. Conforme Orlandi (1999, p. 26),

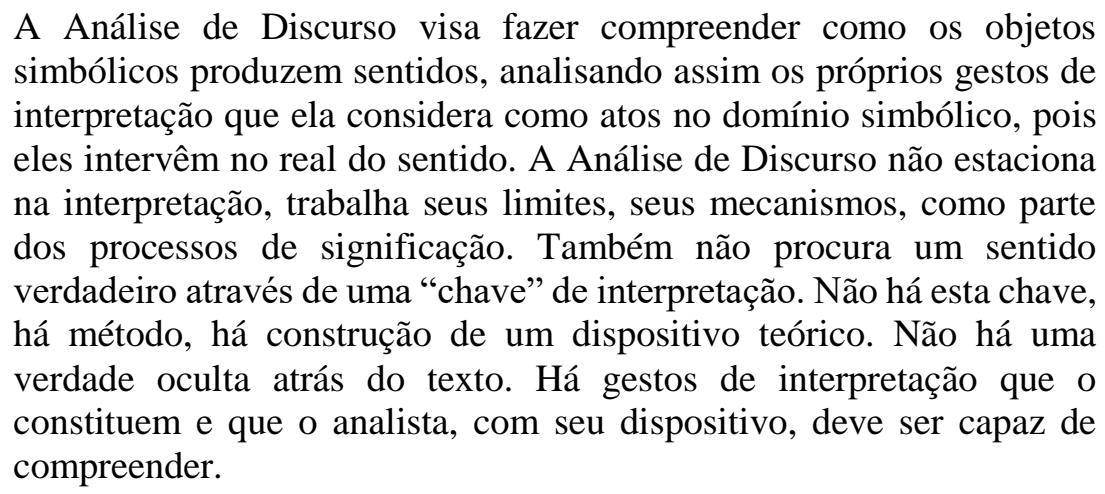

Ainda de acordo com Orlandi (1995, p. 39), "[a matéria simbólica do texto nãoverbal imagético e sua consistência significativa] não são redutíveis ao verbal, embora

\footnotetext{
${ }^{6}$ Possibilidade porque há real, o que impede o fechamento da leitura-interpretação em um sentido único e impossibilidade porque há ancoragem sócio-histórica dos sentidos, de modo que não se trata de qualquer sentido; são sentidos possíveis.
} 
sejam intercambiáveis, sob certas condições. Quando isso se faz, produz-se uma paráfrase". Segundo ela, “os processos parafrásticos são aqueles pelos quais em todo dizer há sempre algo que se mantém, isto é, o dizível, a memória" (ORLANDI, 1999, p. 36; grifos nossos). No entanto, ao parafrasear a imagem por meio de palavras, há um efeito de transparência, de estabilidade de sentidos, de leitura-interpretação uniforme e literal, isso quando não há ressalvas sobre os modos de significância distintos dessas formas textuais.

Diante disso, a AD, na condição de disciplina de entremeio, permite analisar, a partir do seu dispositivo teórico-metodológico, a depender da posição do analista de discurso, o texto não-verbal imagético e expor o olhar-leitor à opacidade de sua materialidade significante. Nesse sentido, consideramos que "o leitor-observador participa, com a bagagem sócio-histórica que o constitui, do processo de leitura" (AGUSTINI, 2007, p. 246), [...] há um indizível-invisível que resta no não-verbal imagético, que "abre lacunas para o leitor-observador se colocar" (AGUSTINI, 2007, p. 249), isto porque o homem é instado a interpretar e a produzir sentidos diante de qualquer objeto simbólico.

Com efeito, verificamos que, a partir dos estudos da $\mathrm{AD}$, dada a natureza do objeto construído pelo analista, há a possibilidade de analisar o texto não-verbal imagético, não como um mero repasse do verbal, mas como uma prática discursiva na qual o real incide e marca a impossibilidade de tudo "dizer"/"mostrar", incompletude que é própria do simbólico. Diante disso, algumas im-possibilidades de leitura-interpretação do texto nãoverbal imagético podem ser, de certo modo, enfrentadas na prática do professor, isso porque não há uma leitura-interpretação única, há subjetividade ${ }^{7}$ posta no ato de lerinterpretar. Desse modo, cabe ao professor, minimamente, expor seus alunos à opacidade do texto não-verbal imagético, sem perder de vista os funcionamentos específicos dessa forma textual.

\section{2. $O$ texto não-verbal imagético no livro didático}

Como dito anteriormente, recortamos para analisar, no artigo em tela, um texto não-verbal imagético presente no livro didático "Português: Linguagens", de William Roberto Cereja e Thereza Cochar Magalhães, referente à edição direcionada aos alunos do $9^{\circ}$ ano do ensino fundamental. Essa é uma obra bastante apreciada pelos professores da educação básica e, por isso, muito utilizada na rede pública de ensino. Nosso interesse, ao selecionar esse livro, é problematizar em que medida o trabalho pedagógico com o texto não-verbal imagético é proposto e em que medida poderia ser feito a partir de um olhar relacional e discursivo, a fim de mostrar que a opacidade deve ser enfrentada/explorada pelo professor. Esse enfrentamento pode contribuir para a formação

\footnotetext{
${ }^{7}$ Não se trata de uma subjetividade solipsista; a subjetividade, de nossa perspectiva teórica, resulta do contraste com o outro e da experiência de linguagem que é única para cada homem. Ou seja, ninguém tem a mesma história de leitura-interpretação, embora haja uma zona proximal, que constitui, em certa medida, a realidade social.
} 
do aluno como leitor, de modo que os aspectos relacional e discursivo da leiturainterpretação sejam contemplados.

Já na introdução da versão do livro direcionada ao professor, há destaque para a quão "inovadora e abrangente" é a proposta apresentada para a prática de ensino de Língua Portuguesa, isso porque, de acordo com os próprios autores, trata-se de uma

\begin{abstract}
proposta de um trabalho consistente de leitura, com uma seleção criteriosa de textos - que vão dos clássicos da literatura universal aos autores da literatura contemporânea brasileira -, comprometida com a formação de leitores competentes de todos os tipos de textos e gêneros em circulação social; uma abordagem de gramática que, sem abrir mão de alguns conceitos de gramática normativa, essenciais ao exercício de um mínimo de metalinguagem - como substantivo, verbo, pronome, complementos, adjuntos -, alarga o horizonte dos estudos da linguagem, apoiando-se nos recentes avanços da lingüística e da análise do discurso; uma proposta de produção textual apoiada na teoria dos gêneros textuais ou discursivos e na lingüística textual; $e$ o interesse em explorar (seja na condição de receptor, seja na de produtor) outras linguagens, além da verbal, como a pintura, a fotografia, o cinema, o cartum, o anúncio publicitário, etc. (CEREJA; MAGALHÃES, 2006. p. 2, grifos nossos).
\end{abstract}

Observamos, na citação acima, a menção de apoio teórico-analítico nos estudos da Análise de Discurso e o interesse em tratar os diferentes tipos de texto. Em relação à essa citação, vale destacar que há menção também à busca de apoio teórico na Teoria dos Gêneros e na Linguística Textual, o que, de saída, coloca certas questões que, no livro didático em foco, não são abordadas. Por exemplo, haveria uma teoria dos gêneros textuais ou discursivos? Como a AD e a Linguística Textual dialogam no livro? Esse diálogo pode ser produtivo, no espaço escolar, para a leitura-interpretação de textos nãoverbais imagéticos? Convocar os nomes de diferentes campos teóricos pode promover um efeito de in-distinção entre eles em relação aos seus fundamentos epistemológicos. Assim, a distinção restringir-se-ia ao foco, de modo que um leitor, sem incursões nesses campos teóricos, poderá concebê-los como um somatório de conhecimentos em relação acumulativa. Já o teórico poderá dizer que, no espaço escolar, ocorre uma espécie de "vale-tudo" ou uma necessidade de apoiar-se em autoridades, não nomeadas, mas acionáveis pela circulação das discussões-problematizações e resultados produzidos pelos campos teóricos, a fim de produzir um efeito de caução científica. Um modo de fundamentar os conhecimentos que seriam mobilizados no livro didático.

Essa postura, além de alimentar uma visão de ciência tradicional e positivista, também promove o afastamento do aluno do fazer científico, uma vez que apresenta os conhecimentos como algo pronto, acabado e aceito. A caução em pesquisas linguísticas é importante, mas é necessário que autores de livro didático, instrumento atualmente fundamental ao ensino na educação básica, atentem para a heterogeneidade dos conhecimentos produzidos sobre a linguagem e seu funcionamento e, assim procedendo, consigam direcionar adequadamente as relações de didatização do conhecimento. Esse é um enfrentamento que, muitas vezes, não é feito por força das condições editoriais e por conta da tradição do ensino. Há uma compartimentação do conhecimento e, em 
decorrência, o efeito de que a gramática não interfere na produção textual e na leitura, e vice-versa. Ou que a produção textual não tem implicação sobre a leitura. Por isso, o conhecimento pode advir de diferentes quadros teóricos que suportariam apenas uma diferenciação de foco. Mas voltemos à nossa análise.

Posteriormente, os autores especificam para o professor a estrutura e a metodologia da obra, destacando a importância das unidades e da divisão de cada capítulo. Entre esses, destacamos uma seção, qual seja: "Cruzando linguagens". Como diretriz para essa seção, os autores apresentam para o professor a seguinte instrução:

É um tópico que aparece sempre que necessário e possível e no mínimo uma vez por unidade. Tem por objetivo proporcionar o estudo comparado entre o texto estudado e outro texto, que apresenta um tipo de linguagem diferente [...] Por meio da comparação, o aluno deve estabelecer semelhanças e diferenças quanto ao tema e/ou quanto aos aspectos composicionais e situacionais dos textos. (CEREJA; MAGALHÃES, 2006, p. 4, grifos nossos)

A partir dessa diretriz, recortamos uma atividade para analisar em que medida esse trabalho comparativo é proposto no livro. Essa atividade compõe a unidade intitulada "A permanente descoberta", que é introduzida da seguinte forma: "Ser jovem depende de pele, de idade, de idéias? Ser jovem se constata na certidão de nascimento ou no espírito de cada um? É possível ser jovem na infância e na adolescência? E na velhice? Será que todo jovem é realmente jovem na juventude?" (CEREJA; MAGALHÃES, 2006, p. 140). Esses questionamentos podem direcionar o aluno para a conclusão de que "ser jovem é algo relativo à mente", uma vez que nas duas primeiras questões os aspectos físicos vêm antes dos aspectos mentais, e o segundo argumento é constituído, por regularidade semântica, de uma força argumentativa proeminente. Na terceira questão, a expressão modalizadora "é possível" funciona como operador argumentativo, já que apresenta o argumento como uma possibilidade; na quarta, o jogo entre o tempo verbal futuro e o advérbio "realmente" são responsáveis por esse direcionamento. Na sequência, os autores apresentam aos alunos a crônica "Ser jovem", de Artur da Távola, que acirra esse direcionamento. Dessa, recortamos o seguinte trecho:

Ser jovem é não perder o encanto e o susto de qualquer espera. É, sobretudo, não ficar fixado nos padrões da própria formação. Ser jovem é ter abertura para o novo na mesma medida do respeito ao imutável. [...] É só pensar na morte de vez em quando. [...] Ser jovem é andar confiante como quem salta, se possível de mãos dadas com o ar. [...] Ser jovem é ter a capacidade do perdão [...] Ser jovem é viver em estado de fundo musical de superprodução de Metro. (CEREJA; MAGALHÃES, 2006, p. 140-141)

Esse trecho da crônica de Artur da Távola mostra a direção que os argumentos tomam para levar o aluno a concluir que "ser jovem é algo relativo à mente", uma vez que as diversas definições apresentadas de "ser jovem" recorrem a aspectos relativos ao pensamento e ao sentimento humano. Após o estudo do texto verbal de Artur da Távola, há a seção "Cruzando linguagens", que solicita ao aluno que observe o texto não-verbal 
imagético abaixo. Nesse caso específico, o texto não-verbal imagético é constituído por uma foto.

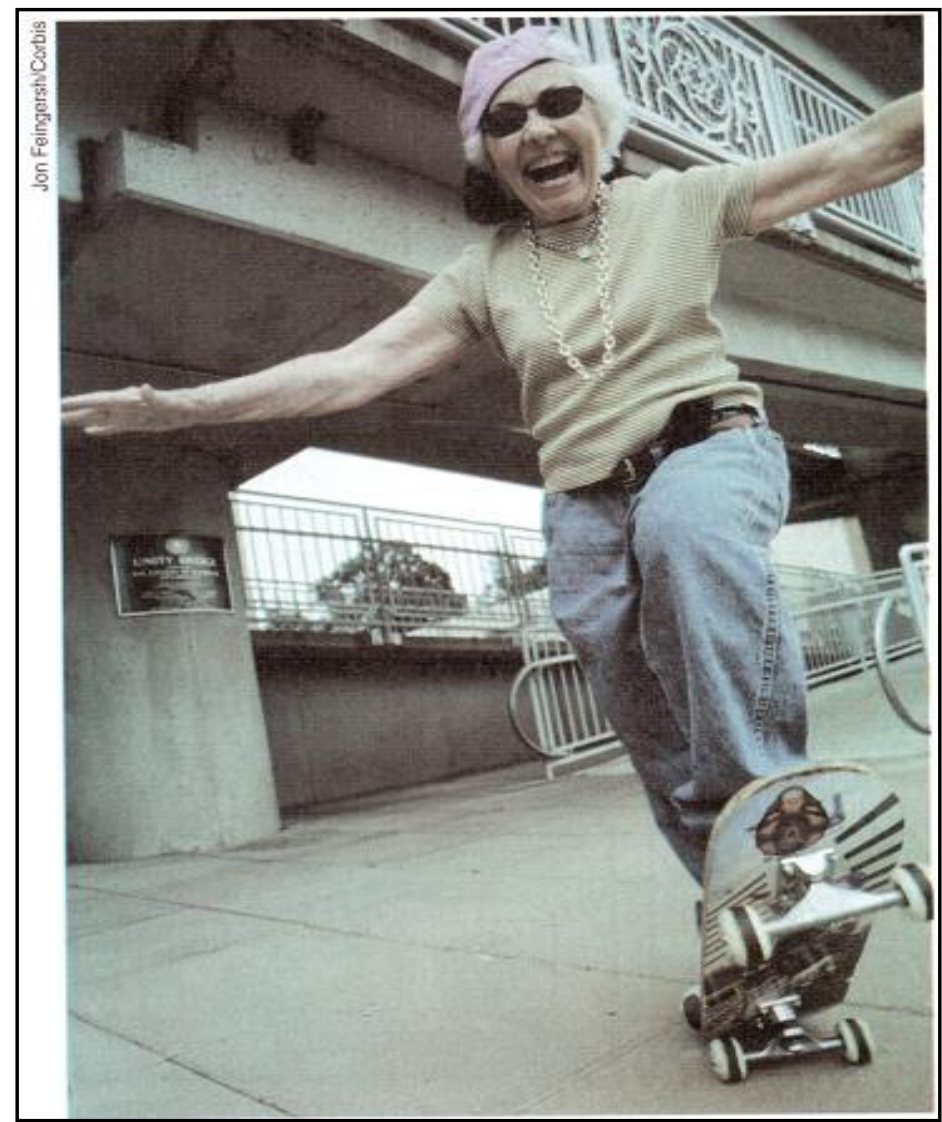

Figura 1. Texto não-verbal imagético presente na seção "Cruzando linguagens".

$\mathrm{Na}$ foto, é mostrada uma mulher idosa, andando de skate, em um espaço de aparência urbana. O ângulo da foto permite observar que ela sorri, ao realizar uma manobra, cujo discurso esportivo significa tal manobra como difícil para um iniciante nesse esporte. Essa descrição que, aparentemente, poderia ser considera neutra, já traz nela questionamentos sobre sua leitura-interpretação. Por exemplo, ela sorri por causa da manobra realizada ou para quem a fotografa? Como decidir sobre uma ou outra possibilidade, se a foto traz nela um recorte e, por isso, um indizível-invisível?

Além disso, esse texto não-verbal imagético é apresentado sem referências às suas condições de produção, o que afeta as possibilidades de leitura-interpretação, uma vez que não há um recorte sócio-histórico e ideológico referido, a não ser o fato de que esse texto não-verbal imagético, dada a sua alocação nessa seção do livro didático, sugere ao aluno que ele será comparado ao texto verbal de Artur da Távola "Ser jovem". Então, ele será lido nessa relação e, como veremos, o texto não-verbal imagético será tomado como mera ilustração do texto verbal, o que reduz a sua leitura-interpretação. Na condição de ilustração, as referências às suas condições de produção tornam-se desnecessárias, já que meramente (re)diria o texto verbal. 
No entanto, se deslocamos esse texto não-verbal imagético de sua relação com o texto verbal de Artur da Távola, a ausência das referências às suas condições de produção abre o seu processo de leitura-interpretação, mantendo-o na equivocidade dos sentidos possíveis. Assim, permanece ao encargo do leitor-observador, determinado sóciohistórica e ideologicamente, produzir relações para sua leitura-interpretação. Dito de outra forma, para ler-interpretar um texto não-verbal imagético adequadamente, a ciência de suas condições de produção mostra-se fundamental. Apresentamos, abaixo, a título de exemplificação da abertura da significância do texto não-verbal imagético, dentre as condições de produção possíveis, quatro possibilidades de inscrevê-la em condições específicas e o que isso pode provocar em termos de leitura-interpretação:

(1) A foto pode constituir o texto não-verbal imagético de uma propaganda de plano de saúde, voltada para o público idoso. Nessa condição, esse texto não-verbal imagético pode significar que os médicos do plano são tão bons que o idoso pode até praticar skate sem equipamentos de segurança/proteção.

(2) A foto pode constituir o texto não-verbal imagético de uma notícia sobre praticantes de skate que não usam os equipamentos de segurança/proteção necessários, criticando-os por sua imprudência ou vangloriando-os por sua coragem e possível destreza.

(3) A foto pode constituir o texto não-verbal imagético de uma placa afixada em uma pista de skate, de modo a poder significar, por exemplo, que o lugar é aberto a praticantes de todas as idades.

(4) a foto pode constituir o texto não-verbal imagético de um panfleto de competição esportiva, de modo a significar que veteranos na prática do skate também podem competir. Ou pode significar que alguém que sempre praticou skate, irá praticá-lo por toda vida, inclusive na velhice; ou que, com a experiência, há skatistas que deixam de usar equipamento de segurança/proteção.

A inscrição do texto não-verbal imagético em condições de produção específicas, como exemplificado anteriormente, afeta a sua leitura-interpretação, delimitando as possibilidades de leitura-interpretação. Esse procedimento mostra, por conseguinte, a relevância das condições de produção no processo de leitura-interpretação de práticas discursivas propostas no livro didático, de modo a evidenciar que o apagamento de suas condições de produção abre o texto não-verbal imagético a sua equivocidade constitutiva. Assim sendo, o professor pode, antes de começar a trabalhar as questões propostas pelo livro didático e de adequá-las à leitura-interpretação do texto não-verbal imagético, mostrar aos alunos que esse tipo de texto, sem menção às suas condições de produção, pode ser interpretado de modos diversos e, assim, ensiná-los que as possibilidades de leitura-interpretação de um texto não-verbal imagético estão relacionadas à conjuntura sócio-histórica e ideológica de sua leitura-interpretação.

Por exemplo, nos anos 70 do século XX, uma mulher idosa praticar skate seria um acontecimento inusitado, praticamente impensável e poderia, por isso, significar que se trata de uma mulher a frente de seu tempo, ou uma desbravadora ou até uma feminista; 
ao passo que, na contemporaneidade, a foto de uma mulher idosa praticando skate já não causa necessariamente esse estranhamento, podendo não constituir, portanto, um acontecimento inusitado. Nessa condição, o texto não-verbal imagético "perde" os trajetos de leitura-interpretação e, por isso, mantém-se na equivocidade, ou seja, mantémse aberto à polissemia, à inexatidão dos sentidos possíveis de a imagem os evocar/acionar nas redes de memória nas quais os alunos estão inscritos. Assim procedendo, o professor pode promover o acesso do aluno a outros modos de conceber o mundo.

Vejamos, agora, o que o livro didático apresenta como questões de leiturainterpretação do texto não-verbal imagético. A partir da observação do texto não-verbal imagético, o aluno é requisitado a responder a algumas questões. No livro do professor há, em azul, a resposta esperada pelos autores do livro didático, conforme é possível verificar na figura (2) abaixo. O professor, de nosso ponto de vista, não deve restringirse às respostas propostas pelo livro, uma vez que o livro didático deve ser compreendido como uma tecnologia auxiliar.

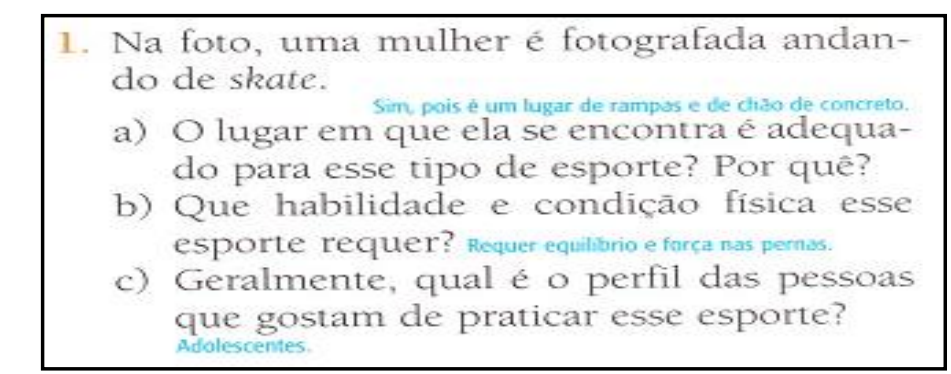

Figura 2. Primeira atividade interpretativa do texto não-verbal imagético.

As respostas propostas pelo livro didático deveriam permitir que o professor expandisse a discussão com os alunos a questões importantes implicadas ao ato de lerinterpretar. Em relação à questão (a), é possível questionar a regulação social do espaço, discutindo se o lugar é realmente adequado, uma vez que a construção não rememora um circuito de skatismo. A resposta da questão (b) pode ser complementada. Ela restringiuse à condição física e não abordou a habilidade. A resposta da questão (c) permite abrir a discussão à problemática dos estereótipos para diferentes compreensões de nossa sociedade, mas isso não está previsto pelo livro. Por que skate seria um esporte geralmente praticado por adolescentes? Em que essas questões relacionam o texto nãoverbal imagético ao texto verbal de Artur da Távola? É somente nessa relação que é possível ler-interpretar esse texto não-verbal imagético?

As questões e as respostas propostas pelo livro didático direcionam a relação entre o texto verbal e o texto não-verbal imagético, de modo a asseverar a conclusão de que "ser jovem é algo relativo à mente". O professor pode, para não se limitar a essa relação, solicitar aos alunos que consultem diferentes dicionários da Língua Portuguesa, inclusive de épocas diversas, a fim de trabalhar as diferentes acepções de "jovem" e de "velhice", por exemplo. Pode, ainda, elencar, com ajuda dos alunos, palavras de sentido similar e, assim, trabalhar a questão da sinonímia de um modo diferente daquele que, tradicionalmente, propõe a gramática normativa, com suas listas descontextualizadas, e 
introduzir a questão da distribuição de usos das palavras, inclusive em relação às expressões idiomáticas. Assim, o professor pode mobilizar esses conhecimentos em função da leitura-interpretação do texto não-verbal imagético e da ancoragem proposta pelo livro via a sua comparação e a sua não comparação com o texto verbal.

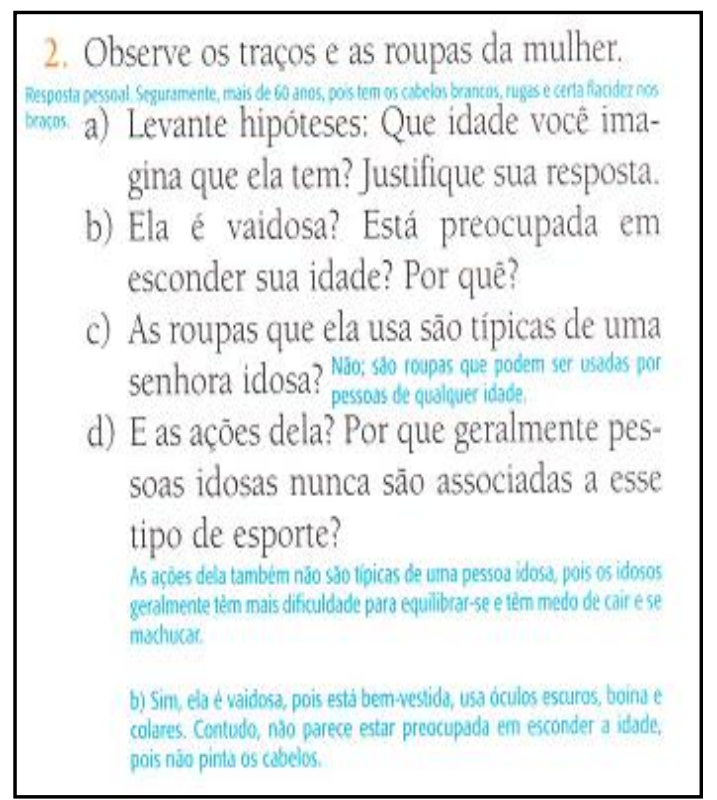

Figura 3. Segunda atividade interpretativa do texto não-verbal imagético.

Nessa perspectiva, se o professor concebe o livro didático como uma tecnologia auxiliar, ele pode expandi-lo e criar uma aula para além de sua delimitação. No entanto, muitas vezes, deparamo-nos com outra realidade. Muitos professores limitam-se às questões e às respostas propostas pelo livro didático, tornando o ensino de leiturainterpretação uma prática atomista e, não, relacional. Assim, o aluno aprende a restringirse ao escrito, no caso do texto verbal, e ao imagético, no caso do texto não-verbal imagético, sem relacioná-los aos aspectos sócio-históricos e ideológicos de sua produção. O aluno acaba por aprender que ler-interpretar é localizar informações no texto e submeter-se à leitura-interpretação já posta por outros.

O livro didático em tela propõe questões e respostas que podem ser consideradas interessantes se o texto não-verbal imagético for tomado na condição de mera ilustração do texto verbal. É preciso, porém, ir mais longe e mostrar como o texto não-verbal imagético pode ser lido-interpretado de modos diferentes e, assim procedendo, colocar em relevo o aspecto relacional e discursivo da leitura-interpretação. Inclusive, o professor pode, nesse sentido, partir da proposta de relação do livro, e propor aos alunos outras relações possíveis. Se a relação de comparação fosse estabelecida a partir de outro texto verbal, o que poderia acontecer com a leitura-interpretação desse texto não-verbal imagético? Como ele poderia ser lido-interpretado na e pela composição verbo-visual, tendo em vista as suas condições de produção? Assim, é relevante dizer que questões sobre o tex to - Como se estrutura? Qual o seu espaço de circulação? A que(m) se destina? - são convocadas ao trabalhar o aspecto relacional e discurso da leitura-interpretação. 
No último bloco de questões, o livro didático propõe a comparação do texto nãoverbal imagético ao texto verbal de Artur da Távola de modo explícito. Elenca várias das definições de "ser jovem" presentes no texto verbal e solicita ao aluno que assinale aquelas definições que cabem também ao texto não-verbal imagético. O professor pode, por sua vez, abrir para novas questões e sentidos. Por exemplo, questionar se a personagem do texto não-verbal imagético está ou não sendo aberta para o novo? Se preconizarmos que a personagem pratica skate desde a juventude, a definição de "ser jovem" como "ter abertura para o novo" ainda se faria adequada? O livro didático não explora/desenvolve nem a leitura-interpretação por ele mesmo proposta. Deixa ao professor o encargo de fazê-lo ao seu modo ou de limitar-se ao que o livro apresenta. Nessa perspectiva, torna-se compreensível o porquê de esse livro ser muito adotado, principalmente na rede pública de ensino.

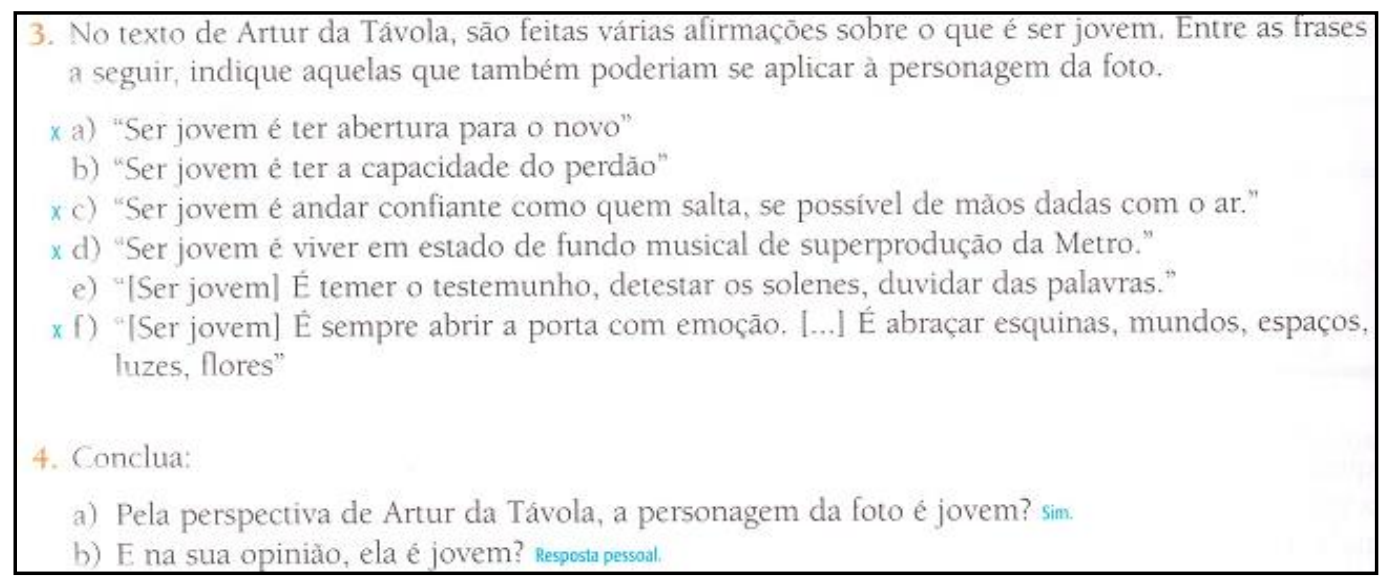

Figura 4. Terceira e quarta atividades interpretativas do texto não-verbal imagético.

Na última questão, a visão do aluno pode ser confrontada à visão do texto verbal, mas é o professor que pode ou não abrir essa possibilidade de modo produtivo. Nesse sentido, o professor pode trabalhar a construção de argumentos do aluno na oralidade e, depois, em um texto dissertativo escrito e re-escrito a partir dos comentários e correções do professor.

Embora tenhamos até aqui feito uma crítica sutil a esse livro didático em relação ao trabalho de leitura-interpretação de textos não-verbais imagéticos, ao considerá-lo apenas uma tecnologia auxiliar do professor, cabe fazermos algumas críticas explícitas, uma vez que ele também é utilizado como instrumento único da prática pedagógica, em alguns casos. Acima, portanto, tentamos mostrar, de modo sucinto, como o professor precisará modelar o livro didático para atingir uma leitura-interpretação que prime por seu aspecto relacional e discursivo, já que o livro didático não o faz. Após a leitura das questões e das respostas propostas por esse livro didático, verificamos que essa edição aborda e explora aspectos bastante pontuais e factuais da fotografia; ele limita-se a explorar a relação entre o texto verbal e o texto não-verbal imagético, de modo que este acaba por funcionar como ilustração do texto verbal. Daí ser necessário o professor 
conceber o livro didático como uma tecnologia auxiliar, base para ir além, de modo a alçar o texto não-verbal imagético a uma unidade que permita ao aluno colocar em relação aspectos específicos da linguagem imagética.

Ao questionar, por exemplo, se "As roupas que ela usa são típicas de uma senhora idosa?" e propor como resposta "Não; são roupas que podem ser utilizadas por pessoas de qualquer idade", pode provocar uma contradição: um idoso não é uma pessoa de qualquer idade? A questão três (3) restringe-se, basicamente, em localizar no texto "Ser jovem" os trechos citados, relacionando-os à imagem. A questão um (1), por sua vez, "O lugar em que ela se encontra é adequado para esse tipo de esporte? Por quê?”, não permite uma resposta que possa, por meio de uma análise do mostrado, ser considerada adequada, já que o recorte da fotografia não possibilita o reconhecimento do lugar. Se considerarmos que, em nossa sociedade, há regulação social dos espaços, o fato de haver uma rampa, como coloca o livro, não autoriza responder afirmativamente a questão. É preciso considerar que os lugares são significados como adequados ou não para determinadas práticas. Assim, há discursos que significam certos locais como adequados à prática de skate e outros, não. Para realizar esse esporte, há locais considerados adequados, e o fato de haver uma rampa no texto não-verbal imagético não significa que se trata de um local específico para sua prática, já que pode se tratar, por exemplo, da entrada de um hospital ou biblioteca. Essa questão pode permitir uma discussão sobre os lugares possíveis para determinadas práticas em função da regulação social do espaço, inclusive de modo a questionar e a discutir o porquê de não ser considerado adequado praticar skate na entrada de um hospital ou biblioteca. Assim, a resposta proposta pelo livro didático reduz o potencial social da questão e faz significar a rampa como elemento naturalizado do discurso sobre a prática de skate. Em decorrência, a imagem funciona como ilustração para o texto verbal que a antecede.

O texto não-verbal imagético apresenta a imagem de uma idosa praticando skate e trajando roupas esportivas. Embora, na atualidade haja uma multiplicidade de imagens acerca do idoso, há sentidos em relação de dominância. Esses sentidos em relação de dominância podem provocar certo estranhamento relativo à situação mostrada na foto, visto que ela testa os limites do corpo para quem está nessa idade. Essa foto, de certo modo, pode desestabilizar certo estereótipo de idoso e certos sentidos a ele relacionados que circulam no Brasil ou, nos termos de Pêcheux, ela pode desestabilizar o logicamente estabilizado acerca do que seria, para uma certa visão sobre o idoso, o seu comportamento, o que pode, inclusive, produzir efeitos de sentido pejorativos, cômicos etc. No entanto, é preciso considerar que essa mesma foto também pode provocar efeitos de sentido de valor apreciativo, enaltecedor etc. Isto porque há discursos em circulação que significam o idoso como dotado de conhecimento e de experiência, com condições de curtir a vida e de aproveitá-la. Nesse caso, o idoso pode ser significado como alguém com estabilidade financeira e tempo disponível para atividades de lazer.

Problematizando sobre a materialidade histórica do texto não-verbal imagético e sobre o suporte em que ele foi exposto, o livro didático, há questões que merecem ser pontuadas em relação às condições de sua produção. Trabalhemos essa questão valendo- 
nos de um jogo de possibilidade de exposição ${ }^{8}$. Por exemplo: se esse texto não-verbal imagético estivesse inserido em uma peça publicitária do Governo Federal tratando do estatuto do idoso ou de alguma política pública voltada para o idoso, a leiturainterpretação seria outra; se essa fotografia estivesse inserida em uma peça publicitária de algum produto farmacológico, a leitura-interpretação seria outra; mas, nesse caso, trata-se de uma fotografia inserida em um livro didático, esse que tem um espaço específico de circulação - o espaço escolar - e que está fortemente ligado aos efeitos do discurso didático, que tem por objetivo pragmático, segundo Charaudeau e Maingueneau (2008, p. 166), "fazer com que o outro aprenda, que vai além do fazer-saber, os discursos didáticos visam aumentar os conhecimentos de mundo". O que isso implica? Esse texto não-verbal imagético, relacionado ao discurso didático, didatiza algo: como lerinterpretar um texto não-verbal imagético. No entanto, essa leitura-interpretação está circunscrita a questões superficiais, que desconsideram os efeitos de sentidos que nela e dela podem emergir e as próprias possibilidades que essa imagem pode contrair em práticas discursivas específicas. Além disso, essa superficialidade impõe uma rarefação da discussão que o livro propõe sobre ser jovem, o que pode comprometer a formação do aluno como ser participante de práticas discursivas.

Assim, o que notamos nas atividades supracitadas são questões superficiais que versam, em certa medida, sobre uma transparência da linguagem não-verbal imagética. Embora na introdução do livro haja ressalvas de suporte nos estudos da Análise de Discurso, isso, de fato, não ocorre; o que os autores propõem é uma análise de conteúdo. Nesse sentido, o fato de o estudo do e sobre o texto não-verbal imagético ter uma problemática epistemológica afeta o campo educacional, já que, embora os autores de livros didáticos a traga para compor os materiais didáticos, ela é explorada a partir de aspectos descritivos e de modo a referendar o que é trabalhado a partir da linguagem verbal, ou seja, como ilustração. Assim, o texto não-verbal imagético não é alçado à sua materialidade própria. Poderíamos dizer que isso afeta o campo do ensino, porque tanto a abordagem dos livros didáticos quanto a abordagem do professor geralmente é de pensar num recobrimento entre essas formas de linguagem, o que abre vias, por exemplo, para ver o que está em função nessa atividade: o texto não-verbal imagético como ilustração, que significaria em si e por si. No entanto, o texto não-verbal imagético (com)porta potencialidades significativas, sendo uma materialidade de outra ordem.

A Análise de Discurso possibilita-nos analisar os efeitos que essa imagem pode produzir no espaço de sala de aula, de modo a sairmos da relação de repasse do verbal para o não-verbal imagético, explorando seu funcionamento significante. Assim, esse texto não-verbal imagético, ao encabeçar a seção "Cruzando linguagens", dialoga, de certo modo, com um tipo de leitura-interpretação que se sustenta no discurso da juventude como fator psicológico e, não, físico, tese defendida na crônica de Artur da Távola. Logo, a fotografia tem por função referendar a tese desenvolvida na unidade, ilustrando-a. Nesse sentido, essa seção "Cruzando linguagens" restringe-se ao cumprimento de diretrizes oficiais, já que "explorar" as diferentes formas de linguagem é algo previsto pelos

\footnotetext{
${ }^{8}$ Esse jogo de possibilidades de exposição do texto não-verbal imagético não é único. Trata-se de um jogo dentre outros possíveis. Vale ressaltarmos que esse jogo é parte de nosso procedimento analítico para demonstrar a relevância das condições de produção no processo de leitura-interpretação do texto não-verbal imagético.
} 
documentos oficiais do Estado. O problema reside no modo como essa "exploração" está proposta no livro didático.

Concluímos, assim, que o uso do livro didático, a depender da concepção que o professor assume de leitura-interpretação, poderá desembocar em aulas diferentes: uma que se baseia na transparência da linguagem e que restringe a leitura-interpretação ao factual do texto e outra que se baseia na não-transparência da linguagem e que busca deslocar a leitura-interpretação do aspecto factual do texto para o aspecto relacional e discursivo.

\section{Considerações provisoriamente finais}

A partir do exposto, tanto da teoria quanto do modo como o livro didático do professor propõe o ensino da leitura-interpretação do texto não-verbal imagético, interrogamo-nos sobre em que medida esse trabalho deveria ser realizado no espaço escolar, tendo em vista as (im)possibilidades de leitura-interpretação enfrentadas pelo professor em sua prática docente. Vimos que a proposta do livro didático encerra discursividades sobre o modo como abordar o texto não-verbal imagético no espaço escolar. Essas discursividades derivam de uma problemática epistemológica sobre a concepção da linguagem imagética como ilustração da linguagem verbal, fato que reflete nos livros e, em certa medida, no fazer docente, que pouco ou quase nada discutem sobre as especificidades da leitura-interpretação do texto não-verbal imagético. Ou seja, não se pontua didaticamente as particularidades da imagem nem se propõe algo para além do descrever o que estaria supostamente posto/mostrado. Nesse sentido, por meio do texto verbal, é possível ler-interpretar o texto não-verbal imagético; no entanto, essa leiturainterpretação não enfrenta a equivocidade da imagem em sua natureza semiótica. Isso porque, como pontuamos anteriormente, o texto não-verbal imagético, assim como o verbal, (com)porta algo do indizível-invisível em sua opacidade que produz efeitos para o próprio ato de ler-interpretar.

Como efeito, o texto não-verbal imagético, como objeto simbólico, convida seu leitor-observador, no mo(vi)mento de leitura-interpretação, a (re)produzir sentidos, novas leituras-interpretações a partir das relações sócio-históricas e ideológicas que o constituem. Diante disso, é importante compreender a impossibilidade de se completar e/ou descrever os efeitos de sentidos que o texto não-verbal imagético produz, já que há real, ou seja, o não-todo, o não-completo do simbólico e, por conseguinte, do sentido. Desse modo, direcionar sentidos ou postular um sentido único para ler-interpretar o texto não-verbal imagético é desconsiderar a potencialidade de sua matéria significante. Logo, é fundamental que o professor, em sua prática docente, pontue as especificidades de cada forma de linguagem, inclusive como matéria de produção textual. Mais: é necessário pontuar a (im)possibilidade de os sentidos serem outros, já que não há uma leiturainterpretação única, visto que há subjetividade, sócio-histórica e ideologicamente situada, implicada no ato de ler-interpretar. O livro didático, nesse sentido, poderia jogar com as possibilidades de inserção do texto não-verbal imagético em práticas discursivas diversas, 
fazendo com que os alunos e os professores, em certa medida, percebam o funcionamento específico de sua materialidade significante.

\section{Referências bibliográficas}

AGUSTINI, C.L.H. Sujeito e singularidade: (n)a enunciação fotográfica. Desenredo, Passo Fundo, v. 3, n. 2, 245-254, 2007.

BRASIL. Ministério da Educação e do Desporto. Parâmetros Curriculares Nacionais: Língua Portuguesa, Brasília, Secretaria de Educação Fundamental, 1997.

CEREJA, W.R.; MAGALHÃES, T.C. Português: Linguagens - $9^{\circ}$ ano. São Paulo: Atual, 2006.

CHARAUDEAU. P.; MAINGUENEAU, D. Dicionário de Análise do Discurso. São Paulo: Contexto, 2008.

DAVALLON, J. A imagem, uma arte de memória? Em: ACHARD, Pierre et al. Papel da memória. Campinas: Pontes, 1999. p. 23-37.

MILNER, J-C. O amor da língua. Porto Alegre: Artes Médicas, 1987.

ORLANDI, E.P. Análise de Discurso: princípios e procedimentos. Campinas: Pontes, 1999.

Efeitos do verbal sobre o não-verbal. RUA, Campinas, Labeurb, Nudecri, no.1, 35-47, mar. 1995.

As formas do silêncio. Campinas: Unicamp, 1992.

PÊCHEUX, M. O discurso: estrutura ou acontecimento? Campinas: Pontes, 2008.

Papel da memória. Em: ACHARD, P. et al. Papel da memória. Campinas: Pontes, 1999. p. 49-57

RODRIGUES, E.A. O efeito do não-verbal no verbal em Primeiras Estórias de Guimarães Rosa. Dissertação. Mestrado em Estudos Linguísticos, Instituto de Letras e Linguística, Universidade Federal de Uberlândia, Uberlândia, MG, 2008. 


\section{Para citar este texto:}

AGUSTINI, Cármen Lúcia Hernandes; ARAÚJO, Érica Daniela de, LEITE, João de Deus. A leitura do texto não-verbal imagético em livros didáticos: reflexões a partir de um olhar discursivo. Entremeios [Revista de Estudos do Discurso, on-line], Seção Temática - Língua(gem) e Ensino, Programa de Pós-Graduação em Ciências da Linguagem (PPGCL), Universidade do Vale do Sapucaí (UNIVÁS), Pouso Alegre (MG), vol. 14, p. 213-231, jan. - jun. 2017.

DOI: http://dx.doi.org/10.20337/ISSN2179-3514revistaENTREMEIOSvol14pagina213a231 